\title{
Synergetic Effect of Nano-carbon and HBN on Microstructure and Mechanical Properties of $\mathrm{Cu} / \mathrm{Ti}_{3} \mathrm{SiC}_{2} / \mathrm{C}$ Nanocomposites
}

Rui Shu ${ }^{\mathrm{a}, \mathrm{b}}$, Xiaosong Jiang ${ }^{\mathrm{a}, \mathrm{b}^{*}}$,Wanxia Liu ${ }^{\mathrm{a}, \mathrm{b}}$, Zhenyi Shao ${ }^{\mathrm{a}, \mathrm{b}}$, Tingfeng Song ${ }^{\mathrm{c}}$,Zhiping Luo $^{\mathrm{d}}$

${ }^{a}$ Key Laboratory of Advanced Technologies of Materials, Ministry of Education, Chengdu 610031, China

${ }^{\mathrm{b}}$ School of Materials Science and Engineering, Southwest Jiaotong University, Chengdu Sichuan 610031, China

${ }^{\mathrm{c}}$ Institut de Ciència de Materials de Barcelona (ICMAB-CSIC), Campus UAB, Bellaterra 08193, Barcelona, Spain

${ }^{\mathrm{d}}$ Department of Chemistry and Physics, Fayetteville State University, Fayetteville, NC 28301, USA

*Corresponding author: xsjiang@swjtu.edu.cn(X.S. Jiang);Tel./Fax: +86-28-87600779.

Abstract: The multiphase co-reinforcing composite combines the advantages of different reinforcing phases to give composite superior properties. In this study, nano-carbon and hexagonal boron nitride $(\mathrm{HBN})$ reinforced $\mathrm{Cu}-\mathrm{Ti}_{3} \mathrm{SiC}_{2}-\mathrm{C}$ composites are fabricated by surface modification, ball milling, vacuum hot pressing (VHP) and hot isostatic pressing (HIP). The content of nano-carbon is $0.5 \mathrm{wt} . \%$, and the ratio of multi walled carbon nanotubes (MWCNTs) to graphene was 4:1,1:1 and 1:4, respectively. Microstructure and mechanical properties of the prepared composites are systematically tested and analyzed. Results show that the interface bonding mode between the reinforcements and matrix is mainly mechanical locking. The composite with the ratio of MWCNTs to graphene is 4:1 shows the best properties in which the hardness, tensile, compressive and shear strength are 121.91 HV, 163.87 MPa, 431.86 $\mathrm{MPa}$ and 122.56 MPa, respectively. The reinforcements improve the properties of 
composites by the mechanisms of load transfer, fine grain strengthening, particle strengthening and anti-friction lubrication.

Key words: MWCNTs; Graphene; HBN; Microstructure; Mechanical properties.

\section{Introduction}

As a functional material with excellent properties, copper matrix composites are widely used in electrode, contact, pantograph slide, magnetic levitation slide, etc [1-3]. With the development of science and technology, the performance requirements of copper matrix composites have been greatly raised, and the copper matrix composites with various reinforcements have been extensively studied [4-7]. Copper matrix composites reinforced with graphite or $\mathrm{Ti}_{3} \mathrm{SiC}_{2}$ were studied extensively as wear-resistant materials, and the graphite reinforced copper matrix composites have been actually applied as slider materials [8-10]. A tribo-film of graphite will form on the composite surface during the process of sliding electrical contact, which reduces the friction coefficient and wear rate of the composite [11]. $\mathrm{Ti}_{3} \mathrm{SiC}_{2}$ combines the merits of both metals and ceramics for its unusual valence bond structure, the layered ternary structure gives it excellent mechanical and tribological properties, and its good wettability with copper is beneficial to form a tight bonding interface [10].

In order to further improving the properties of the composites, carbon nanotubes (CNTs), hexagonal boron nitride (HBN) and graphene are added to the copper matrix as new reinforcing phases [12-14]. CNTs and graphene are both new nano-carbon materials with excellent mechanical, thermal and optical properties, and widely used as reinforcement phase of composite [15-18]. Like graphene, HBN has a hexagonal network structure and is a two-dimensional nano-material with excellent properties, which has been favored by scholars due to its wide application prospect [19]. The addition of these reinforcing phases greatly improves the properties of copper matrix composites and has good application prospects. Chen et al. [20] reported that no matter the aspect ratio of CNTs, it exhibits a strong strengthening effect, while the strengthening mechanism is closely associated with aspect radio. Researches also prove that the fracture mechanism of graphene/Cu composite changes from ductile to 
brittle with the increase of graphene content for forming aggregates [21]. Hence, it is an issue how to improve the dispersion and interface of the nano-reinforcements in composite [22-24].

Different reinforcing phases have their unique strengthening effects. In order to combine the advantages of different reinforcing phases to produce composite with better properties, many scholars have conducted research on multiphase reinforced composites in recent years [25-27]. Multiphase co-enhancement can achieve the effect of " $1+1>2$ ", which provides the possibility to prepare multifunctional composites. Some scholars studied the synergetic effect of graphene and CNTs composites, and found that the synergetic effect of graphene and CNTs improved the dispersion of graphene and CNTs [26]. Under certain conditions, "leaf-like" structure could be formed, and the enhancement effect was significantly improved [28]. According to this idea, the nano-carbon and $\mathrm{HBN}$ reinforced $\mathrm{Cu}-\mathrm{Ti}_{3} \mathrm{SiC}_{2}-\mathrm{C}$ composites which the content of nano-carbon is 0.5 wt.\% and the ratios of MWCNTs to graphene are 4:1, 1:1 and 1:4 are prepared through the process of surface modification[29], ball milling, vacuum hot pressing (VHP) and hot isostatic pressing (HIP) in this work. The microstructure and mechanical properties of the composites are tested and analyzed, then the fracture mechanism and strengthening mechanism are discussed on the basis of experimental results.

\section{Experimental}

\subsection{Materials and composites fabrication}

The raw materials of this experiment include electrolytic copper powders, $\mathrm{Ti}_{3} \mathrm{SiC}_{2}$ powders, graphite powders, HBN, MWCNTs and graphene. The specific properties of the raw material powders are shown in Table 1. The preparation process of the $\mathrm{Cu}-\mathrm{Ti}_{3} \mathrm{SiC}_{2}-\mathrm{C}$ composites with $\mathrm{HBN}$ and various nano-carbon contents mainly includes four parts (as shown in Figure 1). First, the surface modification of MWCNTs and graphene were through ultrasonic agitation for $30 \mathrm{~min}$ with aqueous solution of gallic acid and rutin, respectively. Then mixing the powders by a planetary ball mill (WL-1) for $2 \mathrm{~h}$ and the slurry was dried by a vacuum freeze dryer (FD-A-50). 
Next, bulk composite was obtained via vacuum hot pressing sintering (VHP, VHP-V).

Finally, the bulk composite was densified by hot isostatic pressing (HIP, QIH-15).

Table1. Properties of raw materials

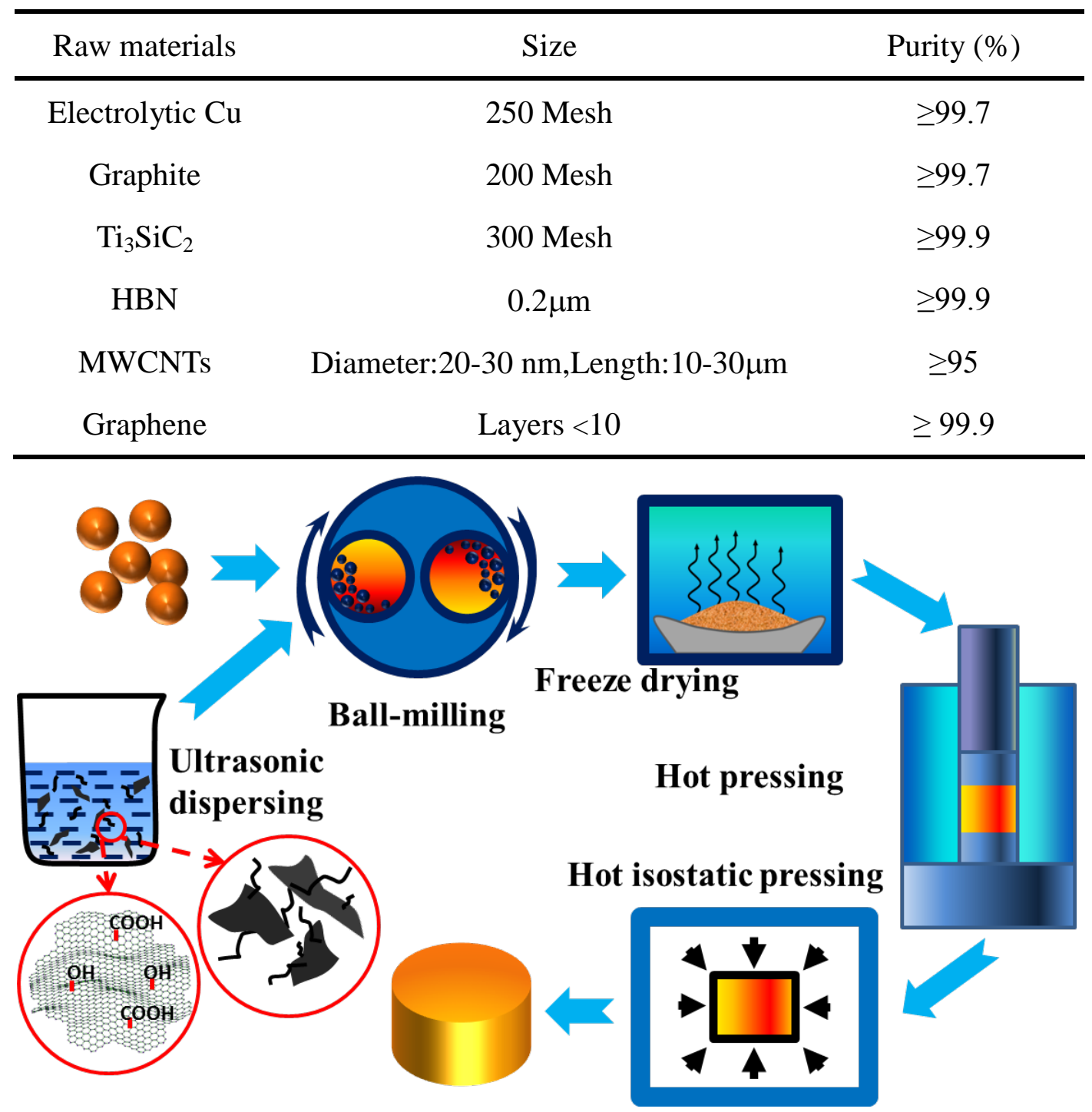

Figure 1. Schematic diagram of the preparation process of $\mathrm{Cu}-\mathrm{Ti}_{3} \mathrm{SiC}_{2}-\mathrm{C}$ composites reinforced with nano-carbon and HBN

\subsection{Characterization of composites}

An X-ray diffraction analyzer (XRD, X. Pert Pro-MPD) was used to analyze the phases of the prepared composite powders and bulk composites. The microstructure of the prepared composite powders and bulk composites was observed by optical microscope (OM, Zeiss Axio Imager. Alm) and scanning electron microscope (SEM, Hitachi S-4800) with energy disperse spectroscope (EDS).The interfaces between different phases and the microstructure of each phase were observed via transmission 
electron microscope (TEM, FEI Tecnai F20ST). The densities of bulk composites were measured by the Archimedes drainage method. The micro Vickers hardness and strength of composites were tested using digital microhardness tester (HVS-30) and electronic universal testing machine (WDW-3100), respectively. And then, the surface morphology of the tensile, compressive and shear fractures was observed and analyzed using a scanning electron microscope (SEM, Hitachi S-4800) with EDS.

\section{Results and discussion}

\subsection{Characterization of $\mathrm{Cu}-\mathrm{Ti}_{3} \mathrm{SiC}_{2}$-C composite powders reinforced with} nano-carbon and HBN

The raw material powders and milling balls were turned at high speed and collided with each other in an agate jar during the planetary ball milling process. The purpose of grinding and dispersion achieved for the effects of shearing, impacting and crushing the powders. Ball milling is not only mixing the various powders but also a process of mechanical alloying between the individual material particles [30]. Figure 2 displays the SEM morphology of the composite powders which the ratio of MWCNTs to graphene is $4: 1$. During the ball milling process, the spherical electrolytic copper powders were deformed into oval or claviform for their low hardness. The phenomenon of cold welding between copper powders can be observed in Figure 2. The large cluster-like particles were formed by the combination of copper powders and other particles (as shown in Figure 2 (a)). In Figure 2(b), it is found that the lamellar reinforcing phases indicated by the red arrows are irregularly embedded between copper particles to form a three dimensional network structure, indicating that the mixing effect is good overall. Previous studies have shown that the higher rotation speed and the longer ball milling time, the more uniform dispersion of the reinforcements and the tighter interface, while the more serious the damage to the structural integrity of the reinforcements [30]. The position of the red cross in Figure 2(b) has been analyzed by EDS, combined with its morphological characteristics, shows that it is agglomerates formed by MWCNTs attached to the surface of HBN, because the adsorption between nano-carbon and $\mathrm{HBN}$ or $\mathrm{Ti}_{3} \mathrm{SiC}_{2}$ is stronger than that between nano-carbon and copper. Nevertheless, the bonding force between various 
reinforcements is pure physical adsorption. Meaning that if using these composite powders to fabricate a block composite later, under external load, the aggregate of reinforcements will undoubtedly cause micro-cracks inside the material and eventually lead to a failure of the entire composite [31]. Therefore, this phenomenon should be avoided as far as possible.
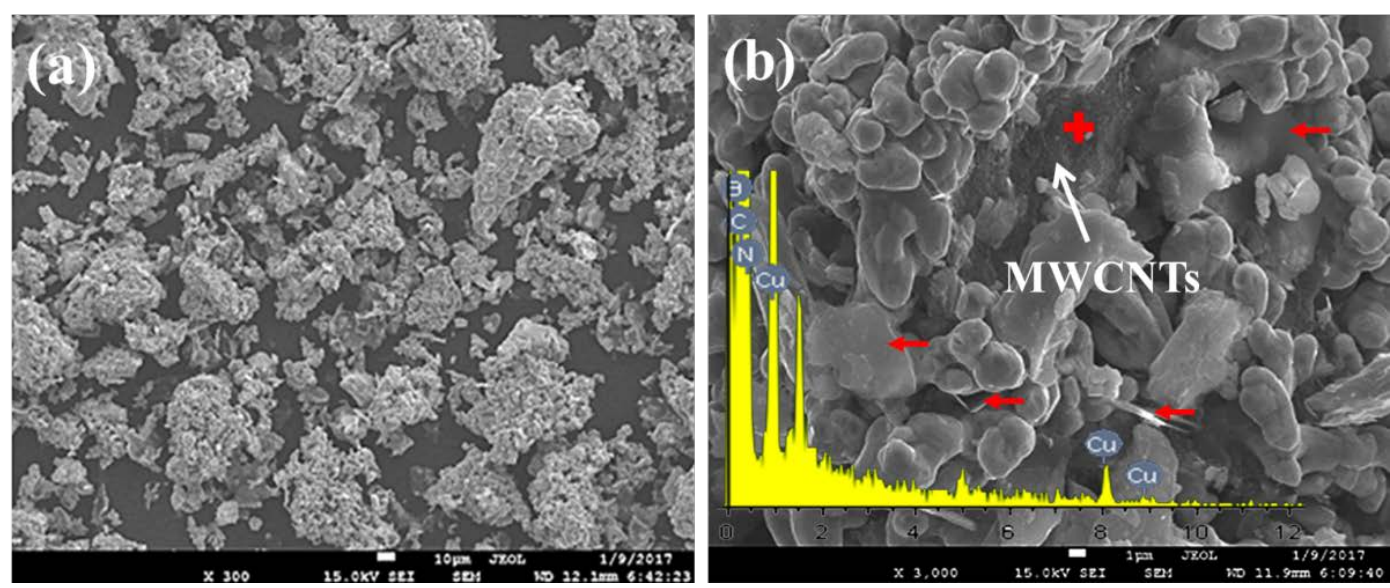

Figure 2. SEM images of nano-carbon and $\mathrm{HBN}$ reinforced $\mathrm{Cu}-\mathrm{Ti}_{3} \mathrm{SiC}_{2}-\mathrm{C}$ composite powders (MWCNTs: Graphene=4:1).

\subsection{Microstructure and phase of $\mathrm{Cu}-\mathrm{Ti}_{3} \mathrm{SiC}_{2}-\mathrm{C}$ composites reinforced with} nano-carbon and HBN

Due to the same fabrication process are adopted and the content of nano-carbon is same as $0.5 \mathrm{wt} . \%$, all the three prepared composites have the same metallographic structures. Figure 3 shows the metallographic structure of the composite which the ratio of MWCNTs to graphene is 4:1. Comparing Figure 3a and 3b, it is found that the microstructure morphology of the planes parallel (Figure 3a) and perpendicular (Figure 3b) to the pressure direction during VHP is the same, owing to the HIP is used for densification. Hence, the prepared composites obtain isotropic microstructure and performance. The uniformly distributed reinforcements can be observed in Figure 3, indicating that the distribution between different phases after ball milling mixture is still maintained, and the sintering process has little effect on it. The black phase is irregularly distributed in the matrix and with no fixed alignment direction, forming a discontinuous three-dimensional network structure in the whole material, which can be speculated as the carbon phase. Gray phase has varies size from microns to tens of microns, with irregularly shape and evenly distributed in white $\mathrm{Cu}$ matrix, speculating 
this is $\mathrm{Ti}_{3} \mathrm{SiC}_{2}$. Varies phases are tightly bonded and no defects like voids are observed from the metallograph, indicating that the density of the prepared composites are excellent.
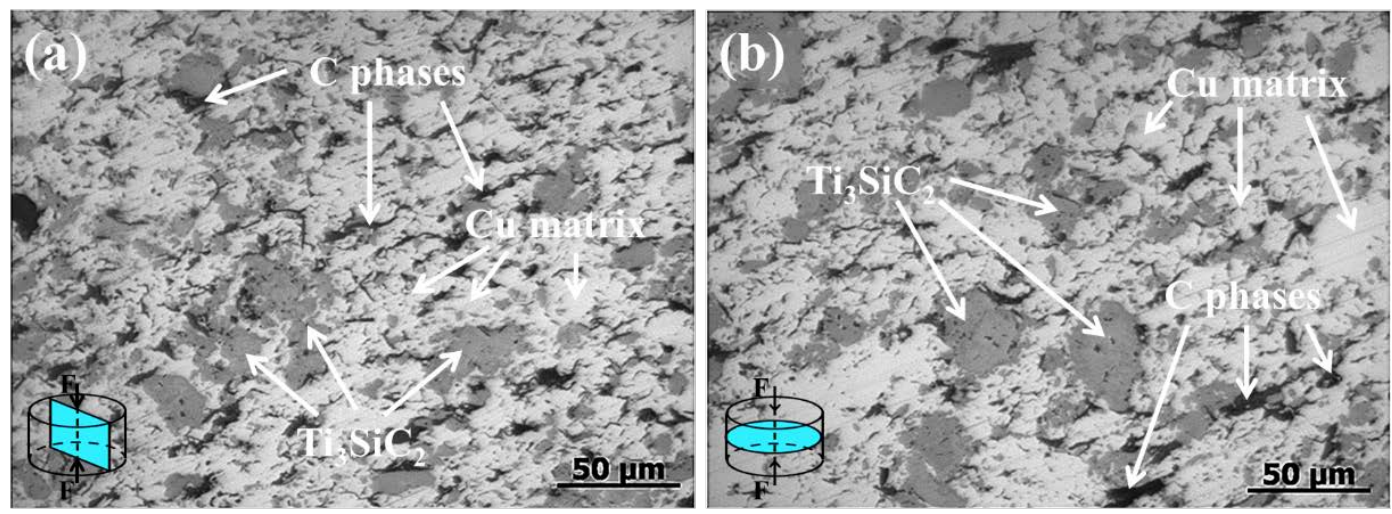

Figure 3.Metallographic images of the nano-carbon and $\mathrm{HBN}$ reinforced $\mathrm{Cu}-\mathrm{Ti}_{3} \mathrm{SiC}_{2}$-C composite (MWCNTs : Graphene=4:1): (a) the microstructure of the plane parallel to the direction of the pressure during hot pressing; (b) the microstructure of the plane perpendicular to the direction of the pressure during hot pressing.

Information on composition and crystal structure of the composites can be analyzed by XRD. Figure 4 shows the XRD results of the prepared three composites with diffraction angles from $20^{\circ}$ to $100^{\circ}$, corresponding to the composites with each ratio of MWCNTs to graphene are 4:1, 1:1 and 1:4. The main peak positions of $\mathrm{Cu}$ in the three composites did not shift from each other, suggesting that the change of nano-carbon has no obvious influence on the crystal lattice size of $\mathrm{Cu}$ matrix. Since the atomic number of $\mathrm{B}$ and $\mathrm{N}$ is small, the content of HBN in the composites is low and the position of the main diffraction peaks of $\mathrm{HBN}$ is close to that of $\mathrm{Cu}$, no characteristic peak of HBN found in the XRD results. The XRD results also detected the existence of $\mathrm{TiC}$, and speculated that there are two reasons for the appearance of TiC. On one hand, the raw material of $\mathrm{Ti}_{3} \mathrm{SiC}_{2}$ contains $\mathrm{TiC}$, which is inevitable for the preparation of $\mathrm{Ti}_{3} \mathrm{SiC}_{2}$. On the other hand, there is thermal decomposition of $\mathrm{Ti}_{3} \mathrm{SiC}_{2}$, and the decomposition products include $\mathrm{TiC}$ and $\mathrm{Si}$ [32]. The phase of $\mathrm{Cu}_{9} \mathrm{Si}$ is detected and presumably that $\mathrm{Si}$ atoms enter copper matrix, forming a solid solution or even a compound. 


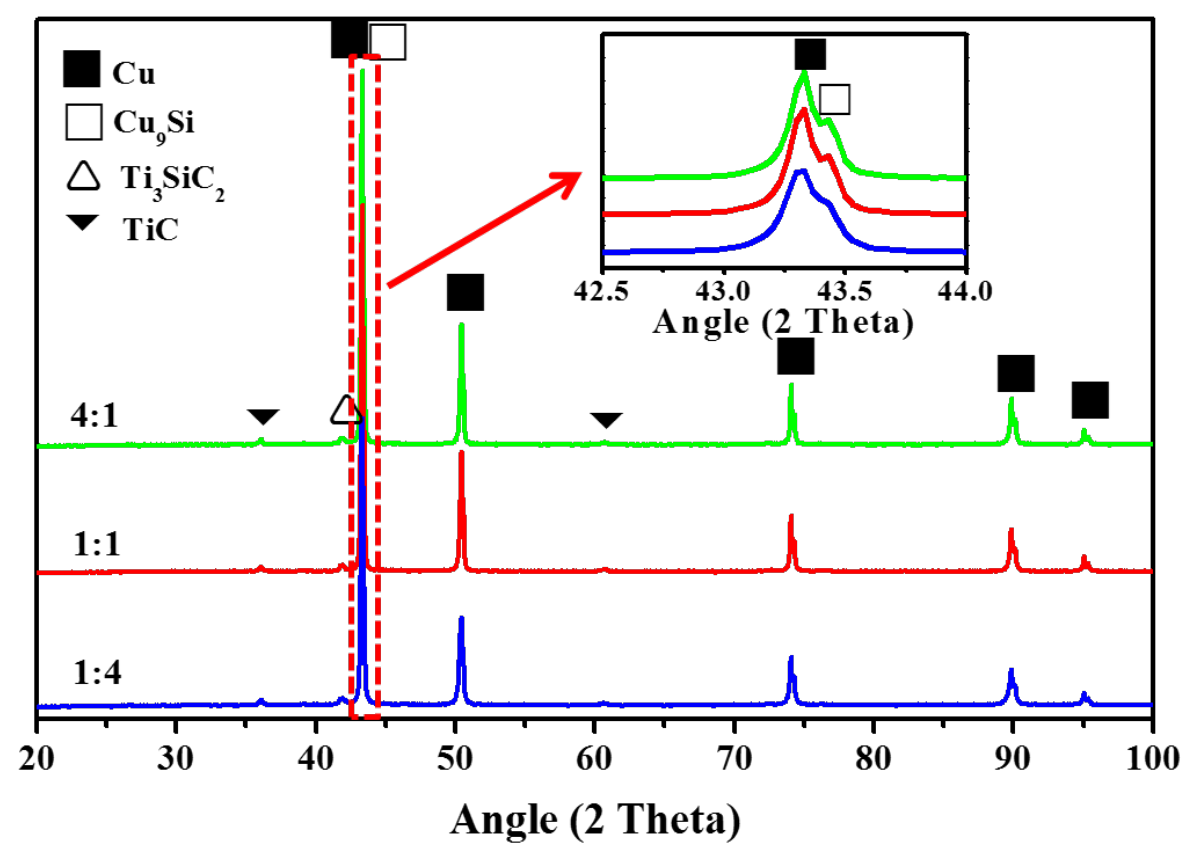

Figure 4. XRD results of nano-carbon and $\mathrm{HBN}$ reinforced $\mathrm{Cu}-\mathrm{Ti}_{3} \mathrm{SiC}_{2}-\mathrm{C}$ composites which the ratios of MWCNTs to graphene are 4:1, 1:1 and 1:4, respectively.

In this work, the possible reactions in the sintering process are further speculated as follows [33]:

$$
\begin{gathered}
\mathrm{Ti}_{3} \mathrm{SiC}_{2}=3 \mathrm{TiC}_{2 / 3}+\mathrm{Si} \\
\mathrm{C}+\mathrm{Si}=\mathrm{SiC} \\
\mathrm{SiC}+9 \mathrm{Cu}=\mathrm{Cu}_{9} \mathrm{Si}+\mathrm{C} \\
\mathrm{Si}+9 \mathrm{Cu}=\mathrm{Cu}_{9} \mathrm{Si}
\end{gathered}
$$

The thermodynamics data at $1000^{\circ} \mathrm{C}$ was used to analyze the reactions, the molar Gibbs generation energy of each material shown in Table 2 [34]. According to the Gibbs free energy calculation formula: $\Delta_{r} G_{m}=\sum v_{B} \Delta_{f} G_{m}$, the Gibbs free energy of the four reactions can be obtained. However, due to the lack of thermodynamic data of $\mathrm{Cu}_{9} \mathrm{Si}$, the values of reaction (3) and (4) cannot be directly calculated. It is observed that (4) - (3) = (2), and (2) $=-66.99 \mathrm{~kJ} / \mathrm{mol}<0$ is also known, indicating that the occurrence probability of reaction (4) is higher than (3) at $1000^{\circ} \mathrm{C}$ under the same condition. This also explains the reason why there is no $\mathrm{SiC}$ in the results of XRD test. 
Table 2. The molar Gibbs generation energy of each material [34]

\begin{tabular}{cc}
\hline Material & Molar Gibbs generation energy $(\mathrm{kJ} / \mathrm{mol})$ \\
\hline $\mathrm{Ti}_{3} \mathrm{SiC}_{2}$ & -520 \\
$\mathrm{TiC}_{2 / 3}$ & -194.06 \\
$\mathrm{Si}$ & -44.33 \\
$\mathrm{C}$ & -20.06 \\
$\mathrm{SiC}$ & -127.38 \\
\hline
\end{tabular}

The surface scanning results of the nano-carbon and HBN reinforced $\mathrm{Cu}-\mathrm{Ti}_{3} \mathrm{SiC}_{2}-\mathrm{C}$ composite (MWCNTs: Graphene $=4: 1$ ) are shown in Figure 5. Figure $5 b$ is the total spectrum map of the area in Figure 5a. Figure 5c-h show the distribution maps of each element of $\mathrm{Cu}, \mathrm{B}, \mathrm{N}, \mathrm{C}$, Ti and Si, respectively. According to results of surface scanning in Figure 5, it can be determined that the white, black and gray phases in Figure 3 correspond to $\mathrm{Cu}, \mathrm{C}$ and $\mathrm{Ti}_{3} \mathrm{SiC}_{2}$, respectively. From Figure 5d and 5e, the distribution of elements $\mathrm{B}$ and $\mathrm{N}$ is consistent, fine and uniform, indicating that HBN distributes in the matrix ideally. The shape of $\mathrm{C}$ is strip and lump, evenly distributed in the whole field of vision (Figure 5f). Ti and Si elements are clumpy and consistent well as shown in Figure $5 \mathrm{~g}$ and $5 \mathrm{~h}$. The boundary between each color block is obviously different and no transition zone of elements observed, because there is no reaction between various phases or the reaction layer is too thin to be observed, which indicates that the combination between phases belongs to mechanical locking, just as in previous reports [33, 35]. 

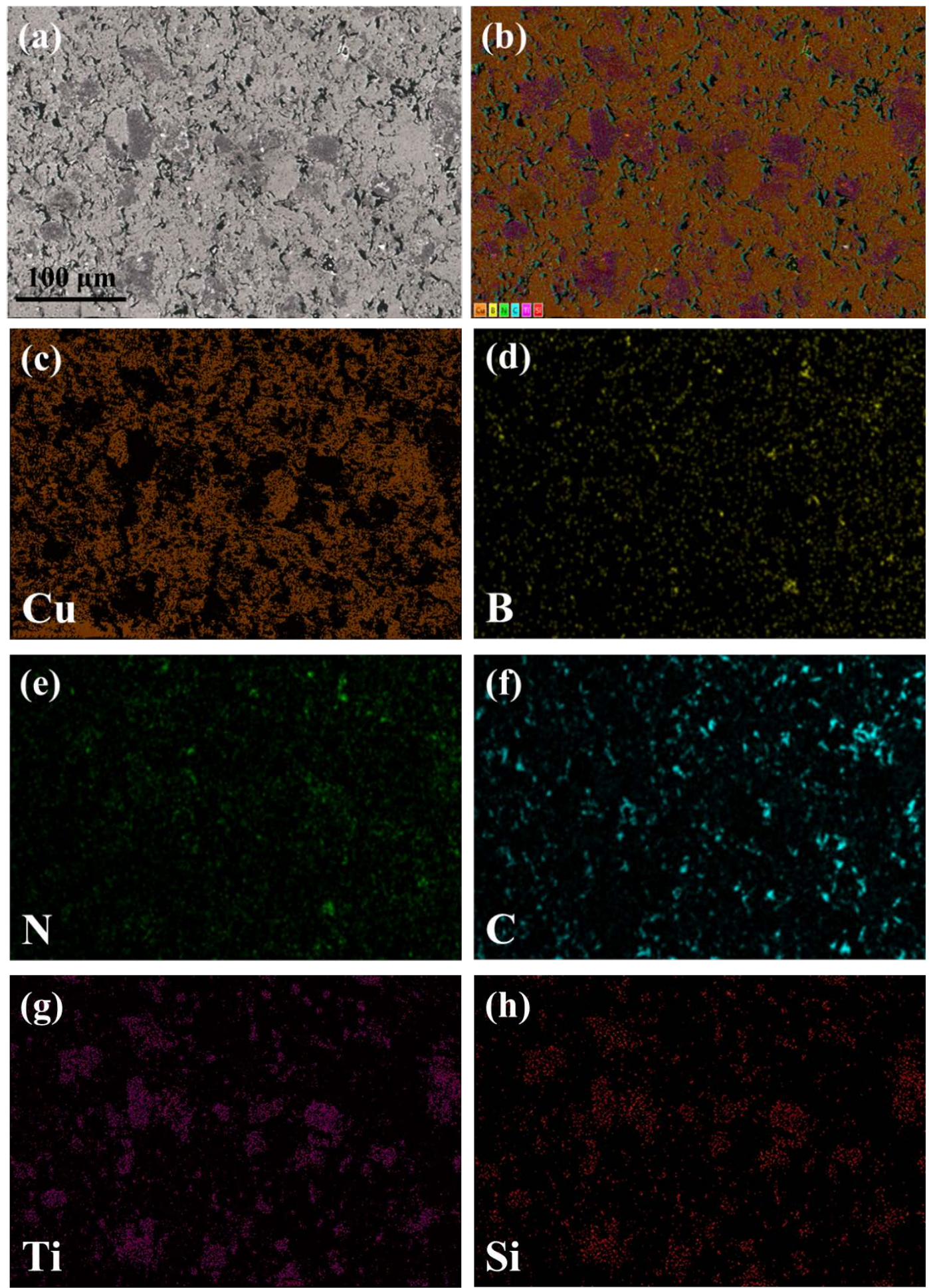

Figure 5. The distribution maps of the elements in nano-carbon and $\mathrm{HBN}$ reinforced $\mathrm{Cu}-\mathrm{Ti}_{3} \mathrm{SiC}_{2}-\mathrm{C}$ composite (MWCNTs : Graphene = 4:1): (a) the SEM image; (b) distribution map of all elements; (c-h) distribution maps of each element of $\mathrm{Cu}, \mathrm{B}, \mathrm{N}, \mathrm{C}, \mathrm{Ti}$ and $\mathrm{Si}$, respectively.

The combination of the reinforcements and the interface can be observed and analyzed at microscopic level by TEM. In the prepared composites, there are three kinds of reinforcements, $\mathrm{Ti}_{3} \mathrm{SiC}_{2}, \mathrm{HBN}$ and carbon phases (MWCNTs, graphene and graphite). Among them, $\mathrm{Ti}_{3} \mathrm{SiC}_{2}$ has both metal and ceramic properties. Hence, it has 
good wettability with copper and can form a close interface [36, 37]. However, for both HBN and carbon are non-metal which are quite different from copper, so the probability of forming a good interface bond is much lower $[13,16]$.

Figure 6 shows the morphology of HBN in the composite and its interface with $\mathrm{Cu}$ matrix. HBN has the same lamellar structure as graphite. Just as single-layer graphite being called graphene, HBN also can be stripped into single layer with extraordinary performance [19]. The EDS result at point 1 in Figure 6a shows that the translucent lamellar phase is graphene-like HBN, which is similar to the results observed in some existing studies [38]. HBN in Figure 6a is not single-layer, but a few layers. The Morie fringe in Figure $6 \mathrm{~b}$ indicates that there is a stack of HBN. Figure $6 \mathrm{~d}$ is a high resolution diagram of the interface position in Figure 6a. The interface binding zone between $\mathrm{HBN}$ and $\mathrm{Cu}$ matrix can be observed, indicating that the mechanical locking between them remains close at atomic level. In Figure 6c, the phases at point 2 and 3 are $\mathrm{Cu}$ and $\mathrm{HBN}$, respectively. It is found that $\mathrm{HBN}$ is embedded in $\mathrm{Cu}$ matrix in strip form by observing the morphology. It is observed that HBN and $\mathrm{Cu}$ contact close and the wetting effect is good from the high resolution diagram (Figure 6f). The strip of HBN is around $40 \mathrm{~nm}$ thick and composed with neat layers. The spacing between layers is calculated to be $0.34 \mathrm{~nm}$, which is speculated to be the (002) crystal surface of HBN by referring to the parameters in the PDF card. The diffraction pattern result of point 3 also confirmed this conclusion (Figure 6e). 

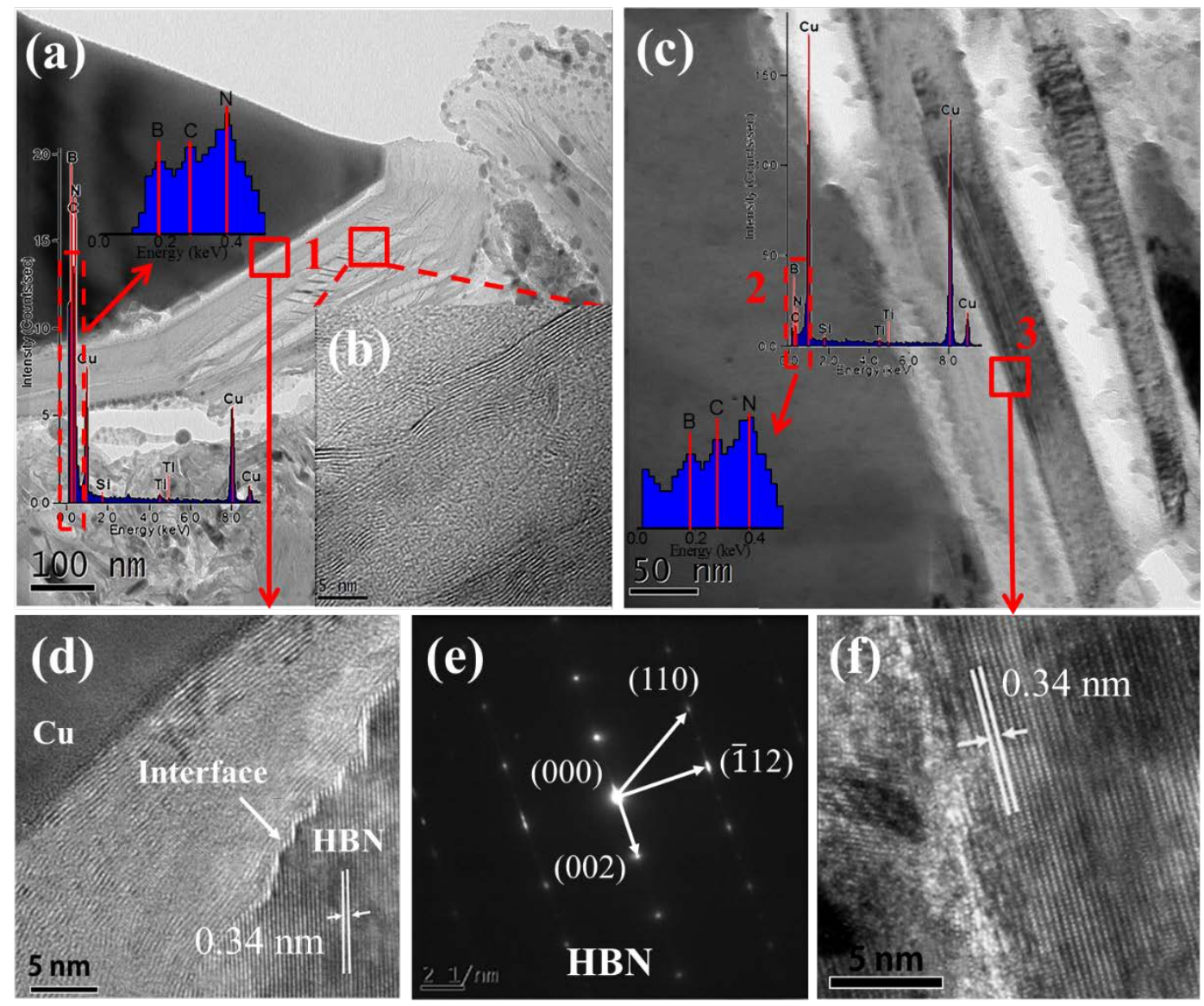

Figure 6. (a) and (c): the TEM images of HBN in the composite (MWCNTs: Graphene=1:4); (b) and (d):the high resolution images of the corresponding regions in (a); (e) the diffraction spots of HBN; (f) the high resolution image of the corresponding region in (c).

A clear difference between reinforcement and $\mathrm{Cu}$ matrix is observed in Figure 7a, reinforcements observed here as MWCNTs and graphene, the distribution and morphology of MWCNTs is clear. Transmission diffraction patterns of MWCNTs and conventional crystal is different. The conventional crystal diffraction pattern spots exhibit a regular parallelogram shape, while the diffraction patterns of MWCNTs appear layered linear shape, and even present polycrystalline diffraction rings when stacking and agglomerating (As shown in Figure 7b). In the transmission topography photo with higher magnification (Figure 7c), the MWCNTs are well rooted and translucent with a complete and smooth radial surface. However, it can also be observed that MWCNTs in Figure 7a are intertwined and agglomerated, and the size of the whole agglomerate reaches the micron level. In terms of size, agglomerated MWCNTs call still play a role in particle enhancement [39]. Here graphene is attached to MWCNTs like a substrate. A few layers of curled translucent graphene 
appear at the edges. Therefore, it is speculated that MWCNTs and graphene mixed and intersected here to form a three-dimensional aggregate of one-dimensional tubes and two-dimensional sheets synthesis [40]. Figure 7c shows the tight bond between the synthesis and $\mathrm{Cu}$ matrix, which the nano-carbon embedded in matrix like a sandwich. Furthermore, it is observed that the combination between the synthesis and matrix is seamless, and some MWCNTs are embedded in copper. Based on the fact that $\mathrm{Cu}$ and $\mathrm{C}$ do not react in this experiment, it is speculated that the chimerism between MWCNTs and matrix is mechanical locking [33, 41].
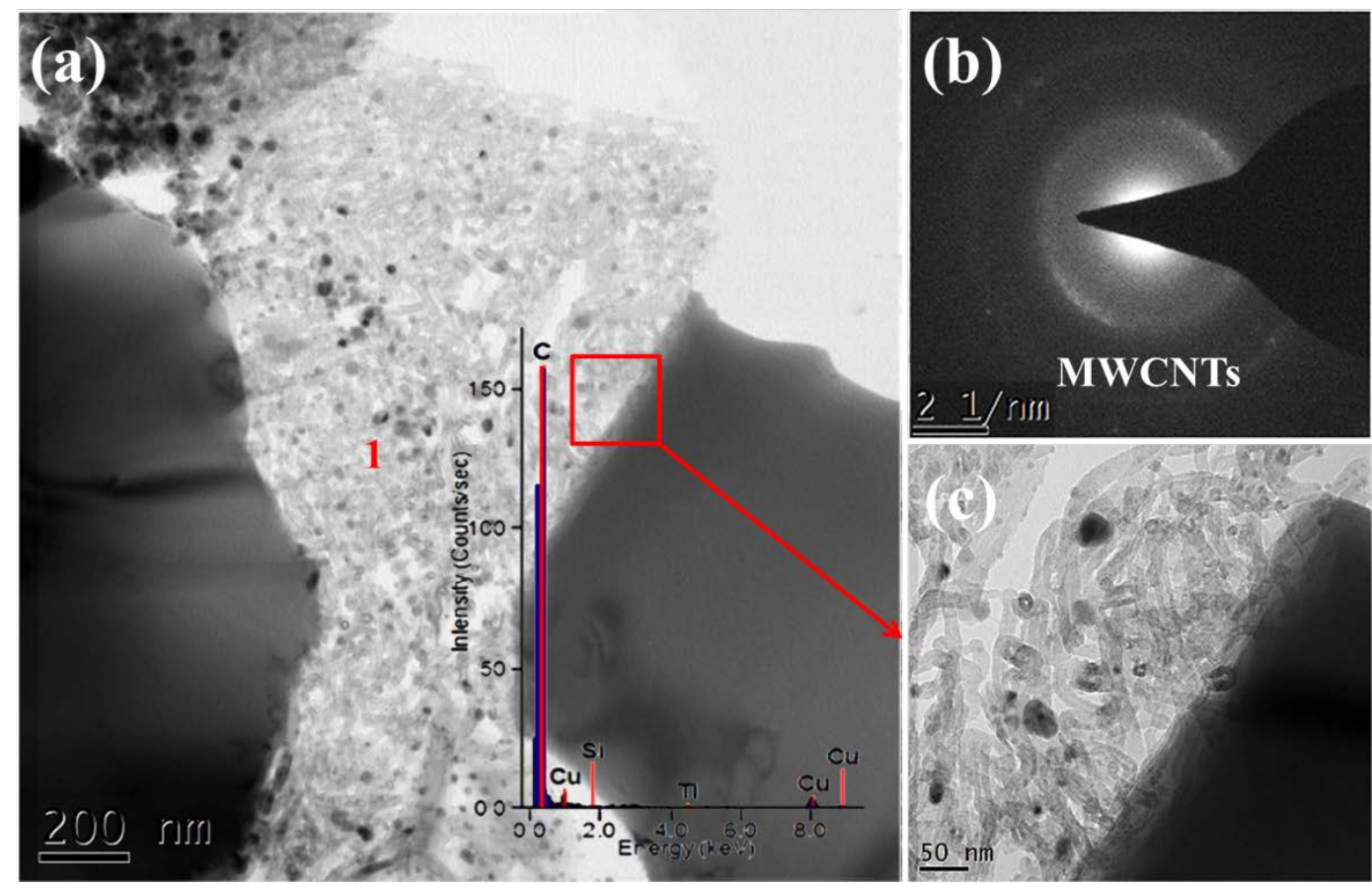

Figure 7. (a) TEM image of MWCNTs in the composite (MWCNTs: Graphene=1:4); (b) the diffraction pattern of MWCNTs; (c) the enlarged image of the corresponding region in (a).

\subsection{Mechanical properties of $\mathrm{Cu}-\mathrm{Ti}_{3} \mathrm{SiC}_{2}-\mathrm{C}$ composites reinforced with nano-carbon} and $H B N$

The densities of the prepared composites were measured by Archimedes method. The relative densities of the three composites are basically the same, which the samples with MWCNTs and graphene ratios of 4:1, 1:1 and 1:4 are 99.83\%, 99.86\% and $99.86 \%$, respectively. It shows that HIP has an outstanding densification effect and almost realizes the complete densification of the material [42]. Since the relative densities of the composites are very similar, determining that the difference on mechanical properties and strengthening mechanisms was caused by the different 
proportions of MWCNTs and graphene in various composites [16, 18]. Figure 8 illustrates the test results of mechanical properties of various composites. It can be observed from Figure 8a that tensile, compressive and shear strengths of the composites decrease successively with the increase of graphene content under the premise that total content of nano-carbon remains unchanged. Hardness shown in Figure $8 \mathrm{~b}$ also shows the same trend. Among them, the composite which the ratio of MWCNTs to graphene is 4:1 shows the best mechanical properties which hardness, tensile, compressive and shear strength are $121.91 \mathrm{HV}, 163.87 \mathrm{MPa}, 431.86 \mathrm{MPa}$ and 122.56 MPa, respectively. The composite with the worst mechanical properties is the composite with a MWCNTs and graphene ratio of 1:4 which hardness, tensile, compressive and shear strength are 114.56 HV, 133.01 MPa, 373.56 MPa and 103.67 $\mathrm{MPa}$, respectively. It is presumed that since the ratio of MWCNTs to graphene is $4: 1$, the dispersion effect of nano-carbon is the best which causing the best reinforcing effect. The strength of the composites in this work is higher than $\mathrm{Cu} / \mathrm{Ti}_{3} \mathrm{SiC}_{2} / \mathrm{C} / \mathrm{MWCNTs}$ composite [33], which indicates that the synergetic effect of nano-carbon and HBN get a better reinforcing effect than single MWCNTs. Figure 8c shows the compressive stress-strain curves of the composites. When the cylindrical specimen was pressed vertically in the radial direction, the composite began to undergo elastic deformation. After reaching the limit of elastic deformation, the yielding platform appears. With the test fore continues to increase, the composite undergoes plastic deformation, and the deformation increases continuously until the composite fails. 


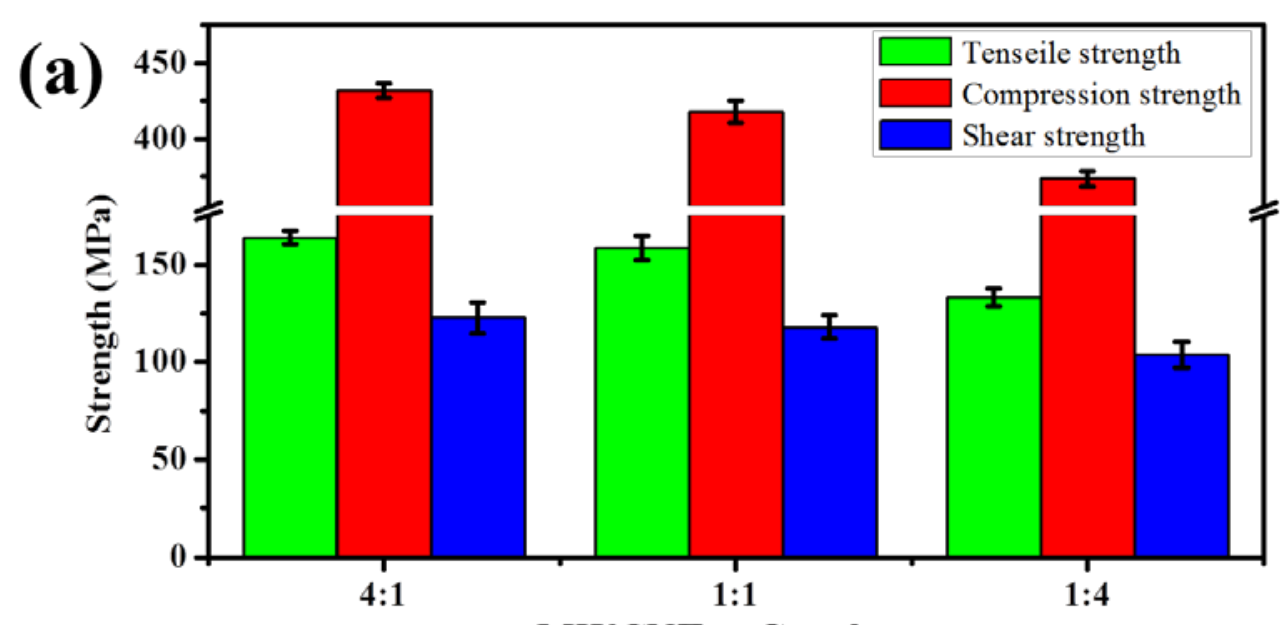

MWCNTs : Graphene
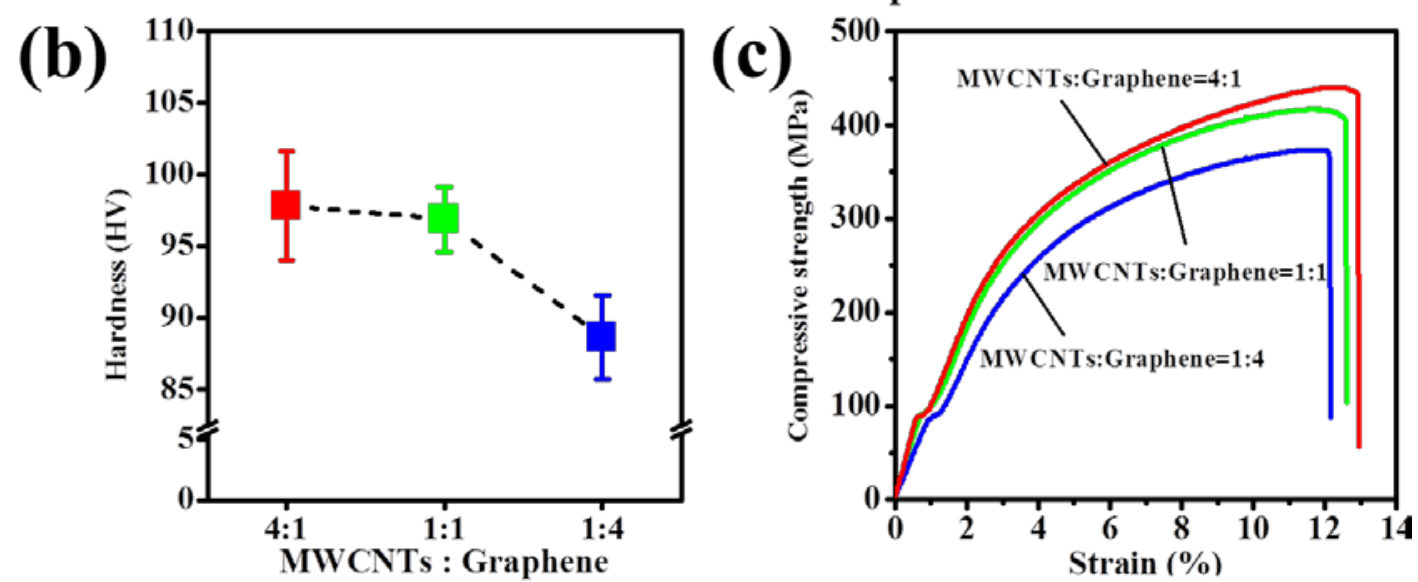

Figure 8. (a) Strength of the nano-carbon and $\mathrm{HBN}$ reinforced $\mathrm{Cu}-\mathrm{Ti}_{3} \mathrm{SiC}_{2}-\mathrm{C}$ composites; (b) Hardness of the nano-carbon and $\mathrm{HBN}$ reinforced $\mathrm{Cu}-\mathrm{Ti}_{3} \mathrm{SiC}_{2}-\mathrm{C}$ composites; (c) Compressive stress-strain curves of the nano-carbon and $\mathrm{HBN}$ reinforced $\mathrm{Cu}-\mathrm{Ti}_{3} \mathrm{SiC}_{2}-\mathrm{C}$ composites.

\subsection{Discussions of fracture mechanisms and strengthening mechanisms}

The SEM and EDS results of a shear fracture of the composite which the ratio of MWCNTs to graphene is 4:1 are shown in Figure 9a. The surface of graphene is clean. On the one hand, the wettability between carbon material and copper is poor, so bond with each other in a mechanical meshing mode and the crack expands along the two-phase interface during the process of fracture. On the other hand, due to the low binding strength of the Van Der Waals force between various graphene layers, the separation between the layers may occur under the action of external forces and forming a crack source [21]. In Figure 9b, an agglomerate of MWCNTs appears, the similar agglomerates are observed in both Figures $2 \mathrm{~b}$ and 7 . Although the size of the agglomerate is micron which still has the effect of particle strengthening, but its strengthening effect is far lower than that of the well-dispersed MWCNTs. And there 
will be a large number of pores in the agglomerate, which will reduce the density of the composite [43].

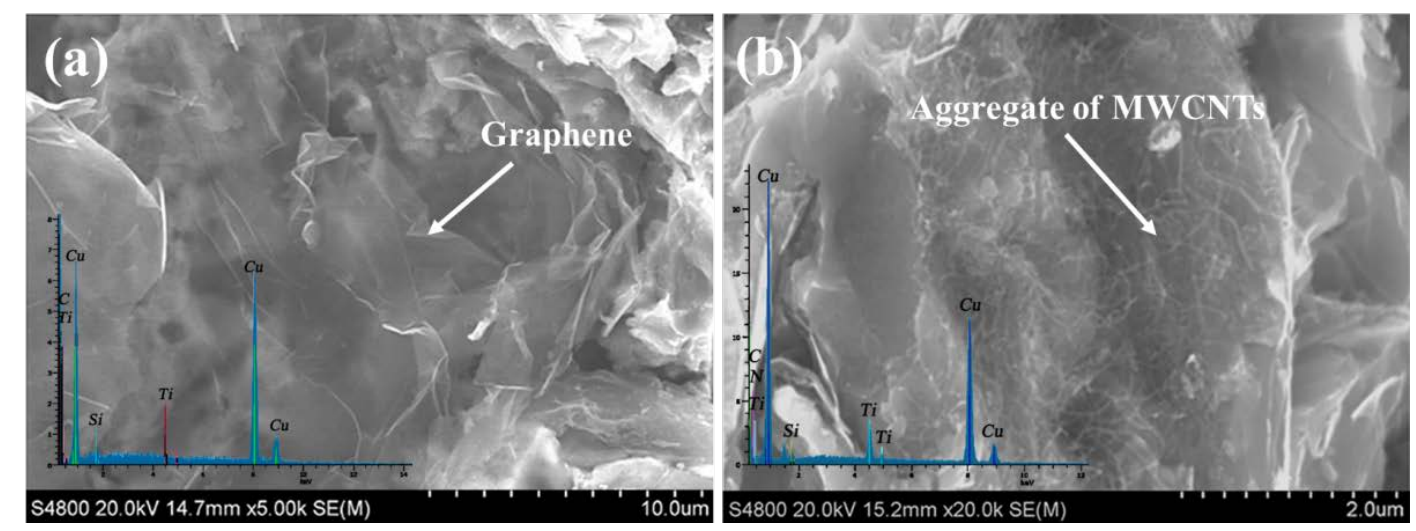

Figure 9. (a) SEM image of the shear fracture of the prepared nano-carbon and HBN reinforced $\mathrm{Cu}-\mathrm{Ti}_{3} \mathrm{SiC}_{2}$-C composite (MWCNTs: Graphene= 1:4); (b) SEM image of the tensile fracture of the prepared nano-carbon and $\mathrm{HBN}$ reinforced $\mathrm{Cu}-\mathrm{Ti}_{3} \mathrm{SiC}_{2}-\mathrm{C}$ composite (MWCNTs: Graphene= 1:1).

Except for the agglomeration of MWCNTs, the addition of graphite with a mass fraction of $3 \mathrm{wt} . \%$ may also be a reason leading to the brittle fracture. Graphite plays an important role in antifriction property of the composite, but its layer structure with a large stack size and has a poor wettability with $\mathrm{Cu}$ [11]. As a granular reinforcing phase in composite, the tensile, compressive and shear resistance properties of graphite are not excellent. Hence, the graphite accumulation is most likely to form pores under an external load, which eventually leads to the failure of the composite. Similarly, HBN is also added to the composite as a layered antifriction material, and too much content will also lead to agglomeration and fracture of the composite [2].

The reinforcement mechanism of composite is usually not alone, but a combination of multiple strengthening mechanisms [40, 44]. In present work, the main strengthening mechanisms includes load transfer [20, 45, 46], fine grain strengthening [40, 47], particles strengthening [15, 20, 45] and thermal mismatch [21, 40]. Here, the strengthening effects can be simply expressed as:

$$
\Delta \sigma_{c}=\Delta \sigma_{L T}+\Delta \sigma_{P S}+\Delta \sigma_{F G}+\Delta \sigma_{T M}
$$

where, $\Delta \sigma_{c}$ is the increase of the strength of composite, $\Delta \sigma_{L T}, \Delta \sigma_{P S}, \Delta \sigma_{F G}$ and $\Delta \sigma_{T M}$ are the improved strength due to load transfer, particles strengthening, fine grain strengthening and thermal mismatch, respectively. Because more than one kind reinforcing phase added in to the composite, each part of the improved strength is a 
synergetic effect of every reinforcements.

The strengthening effect of load transfer in the composite is frequently estimated by shear lag model $[15,20]$. According to the shear lag model, MWCNTs and graphene have the reinforcing effect of shear stress transformation and strengthening on composites, mainly through the transfer of interfacial shear force to share the load on matrix [40]. The reinforcing effect is mainly related to the size and volume fraction of nano-carbon. The yield strength of the composites can be expressed as:

$$
\Delta \sigma_{L T}=s \sigma_{m} V_{f}
$$

where, $\Delta \sigma_{L T}$ is theimproved strength of by load transfer, $\sigma_{m}$ is the yield strength of matrix, $s$ and $V_{f}$ are the aspect ratio and volume of nano-carbon, respectively. In theory, in the case where $\sigma_{m}$ of the metal matrix is constant, the yield strength of composite can be increased by increasing the aspect ratio and volume of nano-carbon. However, in the actual experiment, the higher of volume fraction, the easier to reunite of nano-carbon, microporous gathered themselves together, and porosity increases, resulting a reduction of the properties of the composites, which accord with the actual experimental results [21, 43].

MWCNTs and graphene in the composites do not strengthen the composites separately, but coordinated with each other to form a three-dimensional combination as shown in Figure 7, which achieves a "1+1>2” reinforcement effect [40]. Figure 10 shows the formation of the three-dimensional structure of MWCNTs and graphene. Xiong et al. [48] used a two-step method to fabricate a graphene oxide (GO) and carbon nanotubes (CNTs) reinforced polyaniline hybrid. And found that the interaction between GO and CNTs not only improved their dispersion in the matrix but also formed a three-dimensional GO-CNTs structure which combines the advantages of both nano-carbon materials and shows a better strengthening effect than each single reinforcement. Tough CNTs act as a skeleton with great reinforcing effect, and the two-dimensional graphene wrap around them to form a "leaf” [28]. The large surface area of graphene enables the contact between reinforcement and matrix to be more complete and the bond to be tighter. At the same time, HBN is also a part of load transfer for its high strength, unique structure and tight bonding with matrix (as shown 
in Figure 6). Otherwise, HBN has some properties like graphene as the structure like it, it also can form a three dimensional structure with MWCNTs as the process shown in Figure 9 [27].

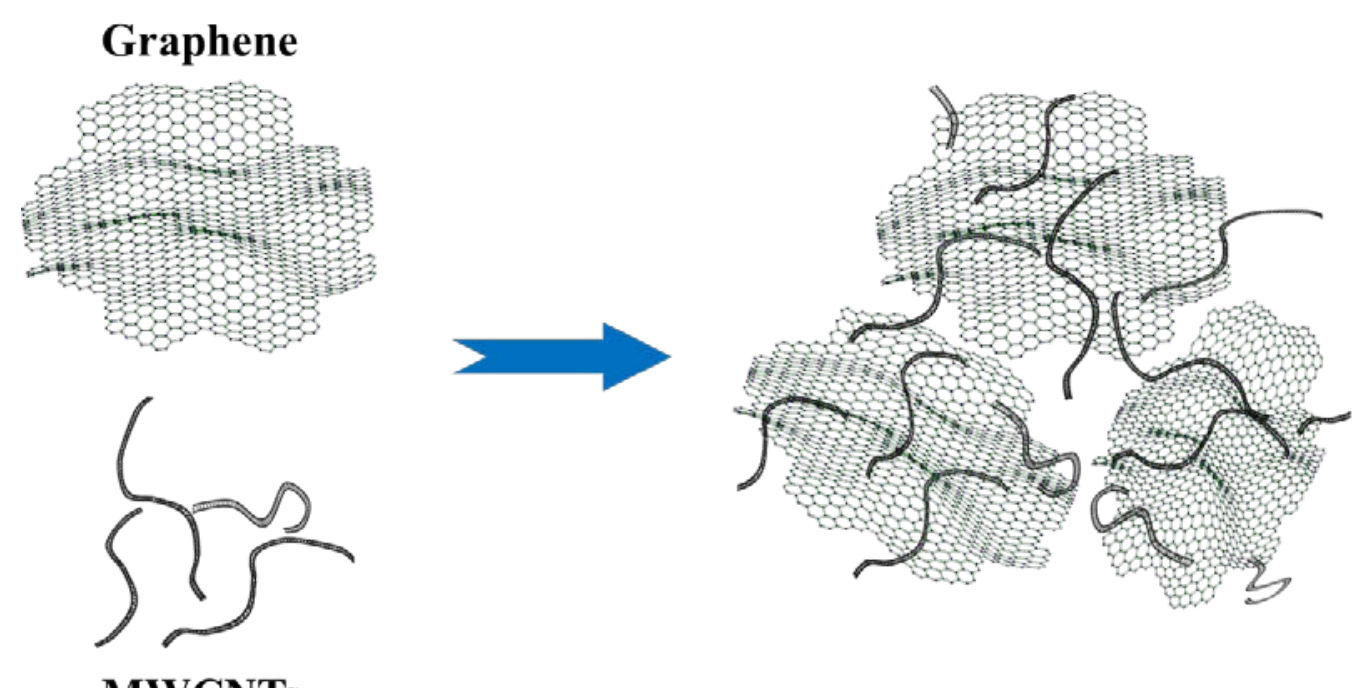

\section{MWCNTs}

Figure 10.Schematic diagram of three-dimensional structure of MWCNTs-graphene.

The interfacial strengthening mechanism caused by the super-large surface of graphene plays an important role in the composite. Figure 11a and 11b are SEM images of tensile fractures of the composites with the ratios of MWCNTs to graphene are 4:1 and 1:4. There are many wrinkles and overlaps on the surface-clean graphene in Figure 11a. The reason for this phenomenon is that the large specific surface area of graphene causing a very high surface energy, so it has a trend to form wrinkles [49]. Moreover, the graphene used is not a single layer, the overlapping portion can be observed. The special structure of graphene enables it to absorb and consume stress through stretching under external forces [15]. The graphene partially embeds in the matrix and the surrounding copper matrix is in the form of tensile tear. The structure of graphene remained intact in the field of view, indicating that the structural integrity of graphene was little damaged during the preparation process. The graphene is very thin and tightly contacts with the $\mathrm{Cu}$ matrix grains, which is beneficial to the transfer of external forces from matrix to graphene, so that the ultra-high strength of graphene can be directly used to achieve a high strength [46]. Graphene has unique wrinkle structure, and there is a process of fold flattening and then breaking during the loading process. Furthermore, graphene itself has good plasticity, so the toughening 
mechanism of graphene on the composites mainly includes super-large interface strengthening, shear stress transfer strengthening and the strengthening of its unique wrinkle structure [15]. It is observed that the number of graphene layers is between 3 and 5 from Figure 11b. On both sides of the graphene are the matrix, and the graphene is not flush with the surrounding matrix and partially protrudes from the matrix. This phenomenon was also observed in previous reports [14, 35]. There are two possibilities for this phenomenon. Firstly, graphene may be taken out by the fractured part of the matrix during the tensile process. Secondly, there is a gap between graphene and the fractured part of the matrix, which may lead to disconnection between graphene and matrix. The both possibilities are attributed to the same reason of poor wettability and low interfacial bonding strength between graphene and $\mathrm{Cu}$ matrix [40]. MWCNTs are also observed around graphene, indicating that this is the three-dimensional nano-carbon structure formed with flattened graphene and smooth surface MWCNTs. When suffering from an external load, the three-dimensional structure can rapidly absorb the stress generated by the surrounding matrix through unfolding, and the external force is borne by MWCNTs through interface stress transfer, thereby achieving the purpose of improving the properties of the composites. Figure 11c shows the variation of the three-dimensional structure with various alignment directions during the tensile fracture process. Among them, the graphene arranged perpendicular to the stress direction is more likely to form a crack source, while the graphene aligned parallel to the tensile stress direction can effectively hinder the crack propagation or change the crack propagation direction. This is the reason why some scholars adopt lamellar structure in order to obtain a material with high properties in a certain direction $[6,50]$. 

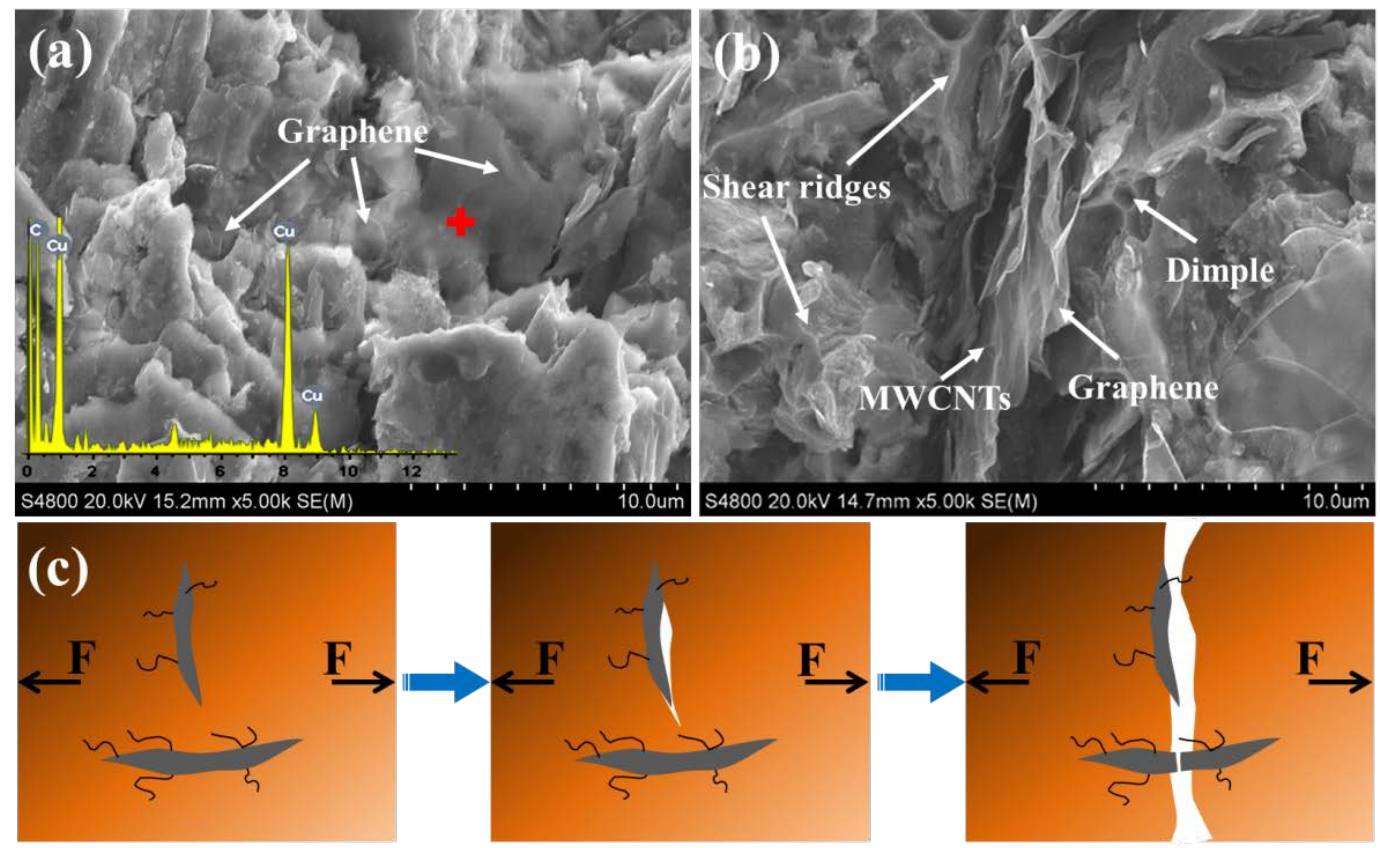

Figure 11. (a-b) :SEM images of the tensile fractures of the prepared nano-carbon and HBN reinforced $\mathrm{Cu}-\mathrm{Ti}_{3} \mathrm{SiC}_{2}-\mathrm{C}$ composites: (a) MWCNTs: Graphene= 4:1; (b) MWCNTs: Graphene= 1:4. (c) Schematic diagram of tensile fracture process.

In addition to the specific strengthening mechanism of nano-carbon, the dispersed reinforcements can improve the strength by inhibiting propagation of dislocation. The Orowan looping system can be used to explain this phenomenon and the improvement can be calculated by following equation [40]:

$$
\Delta \sigma_{\mathrm{PS}}=0.13 \mathrm{~Gb} / \lambda \ln \left(\mathrm{d}_{\mathrm{P}} / 2 \mathrm{~b}\right)
$$

where, $G$, and bare shear modulus and Burgers vector of matrix, $\lambda$ is the effective planar inter-particle spacing and $d_{P}$ is the reinforcement particle diameter. In this work, the reinforcements mainly include three-dimensional MWCNTs-graphene structure, two-dimensional $\mathrm{HNB}, \mathrm{Ti}_{3} \mathrm{SiC}_{2}$ particles and graphite. The shape of each reinforcement is different, $d_{P}$ of the three-dimensional MWCNTs-graphene structure can be estimated by the equation of $\mathrm{d}_{\mathrm{P}(3 \mathrm{D})}=\sqrt{3\left(w t l_{\text {graphene }}+x S l_{M W C N T S}\right) / 4 \pi}$, where, $w, t$ and $l_{\text {graphene }}$ are the width, thickness and length of graphene, $x, S$ and $l_{\text {MWCNTS }}$ are the quantity, cross sectional area and length of MWCNTs [40]. $\mathrm{d}_{\mathrm{P}(\mathrm{HBN})}=\sqrt{3 w_{H B N} t_{H B N} l_{H B N} / 4 \pi}$ can be used to calculate the $\mathrm{d}_{\mathrm{P}}$ of HBN, where $w_{H B N}, t_{H B N}$ and $l_{H B N}$ are the width, thickness and length of HBN [45]. The size of $\mathrm{Ti}_{3} \mathrm{SiC}_{2}$ and graphite in composite ranges from several to tens of microns (as shown in Figure 3), and the wettability with $\mathrm{Cu}$ matrix is good, therefore, it can play a role in 
particle strengthening well [37].

The addition of the reinforcing phase also acts as fine grain strengthening [21, 43]. As we all know, the Hall-Petch formula is an important expression to describe grain boundary strengthening:

$$
\sigma_{\mathrm{FG}}=\sigma_{0}+\mathrm{K}_{\mathrm{s}} \cdot \mathrm{d}^{-1 / 2}
$$

where, $\sigma_{\mathrm{s}}$ is the yield strength, $\sigma_{0}$ is the peierls stress, $\mathrm{K}_{\mathrm{s}}$ is the lattice disorder strength coefficient and dis the grain diameter. Zhang et al. [47] reported that graphene can refine grain of $\mathrm{Cu}$ composite and found that the average grain size in the graphene-Cu interaction zone is much smaller than outside grains, because graphene can provide numerous nucleation sites for $\mathrm{Cu}$. The addition of $\mathrm{HBN}$ also can improve $K_{s}$ and hinder grain boundary movement, result in refining the $\mathrm{Cu}$ matrix grain [13]. Besides, the process of ball milling deforms the $\mathrm{Cu}$ grains and causes the phenomenon of machining hardening, and then recrystallization occurs and the grain is refined during sintering process [21]. The finer the crystal grains, the more the number of grain boundaries, and the better the strengthening effect. The mechanism of grain boundary strengthening is ultimately due to the existence of grain boundaries, which hinders the movement of dislocations, thus achieving the purpose of strengthening. Due to the increase of grain boundaries in the matrix, the incongruity of elastic deformation and plastic deformation at grain boundaries will increase under external load, which tends to induce stress concentration and cause secondary slip near the grain boundary, leading to the rapid proliferation of dislocation, forming the microregion of machining hardening, preventing dislocations from continuing to move. In addition, when the slip dislocation encounters the grain boundary, it is difficult to directly pass through the grain boundary and the dislocation movement is hindered, since the continuity of $\mathrm{Cu}$ matrix is destroyed. Therefore, the addition of nano-carbon and HBN can not only improve the strength of the composite, but also improve its toughness.

Moreover, the coefficient of thermal expansion (CET) of reinforcements and $\mathrm{Cu}$ matrix has a significant difference, which results in dislocation generation [15]. The 
strengthening effect of the mismatch of CET between reinforcements and matrix can be calculated by the following equation [51]:

$$
\Delta \sigma_{\mathrm{TM}}=\alpha \mathrm{Gb} \sqrt{12 \mathrm{~V}_{\mathrm{f}} \Delta \mathrm{CET} \Delta \mathrm{T} / \mathrm{bd}_{\mathrm{P}}}
$$

where, $\alpha$ is a constant, $\triangle \mathrm{CET}$ and $\Delta \mathrm{T}$ are the CET mismatch between reinforcements and $\mathrm{Cu}$ matrix and the maximum temperature change during the fabrication process, respectively. Considering the same graphite structure of MWCNTs and graphene, the values of $\triangle \mathrm{CET}$ between $\mathrm{Cu}$ matrix and the nano-caron with various ratio of MWCNTs to graphene is similar [40]. Hence, the strengthening effect of the mismatch of CET in different composites is mainly influenced by the effective content and size of nano-carbon.

Summary, the strengthening effect of the composite is a result of synergistic action of various reinforcements and mechanisms. In the present work, the various ratio of MWCNTs to graphene mainly influences the dispersibility and the three-dimensional structure of nano-carbon. $\mathrm{HBN}$ and $\mathrm{Ti}_{3} \mathrm{SiC}_{2}$ show tight interfaces with $\mathrm{Cu}$ matrix result in a great improvement of the composite. $\mathrm{HBN}, \mathrm{Ti}_{3} \mathrm{SiC}_{2}$ and graphite also play important roles to improve the tribological property of the composite, while graphite may cause a decrease of strength for its low intrinsic strength and poor wettability with $\mathrm{Cu}$ matrix.

\section{Conclusions}

1. Under the premise of total content of MWCNTs and graphene of $0.5 \mathrm{wt} . \%$, the nano-carbon and $\mathrm{HBN}$ reinforced $\mathrm{Cu}-\mathrm{Ti}_{3} \mathrm{SiC}_{2}-\mathrm{C}$ composites which the ratios of MWCNTs to graphene are 4:1, 1:1 and 1:4 are fabricated by a road of surface modification, ball milling, hot pressing and hot isostatic pressing. The microstructures of the composites are investigated, and the influence of the change of the ratio of MWCNTs to graphene on mechanical properties of the composites is found by analyzing the dispersion, bonding and the strength.

2. The composites are basically completely dense after hot isostatic pressing densification sintering. The synergistic reinforcement effect of the multiphase multi-scale enhancement phase is significantly higher than that of MWCNTs or 
graphene alone. When the ratio of MWCNTs to graphene is 4:1, the composite shows the best properties that the hardness, tensile, compressive and shear strength are 121.91 HV, 163.87 MPa, 431.86 MPa and 122.56 MPa, respectively. The fracture mechanism of the composites is mainly brittle fracture.

3. The interface between reinforcements and the matrix is tight, and proving that the interface bonding mode between the nano-carbon, HBN and matrix is mainly mechanical locking. Graphene can effectively transfer and absorb stress by virtue of its super large interface and unique fold structure. MWCNTs can improve the yield strength of composites through shear stress transformation and bridging by relying on the ultra-length-diameter ratio. Other reinforcing phases improve the properties of composites by means of fine grain strengthening, particle strengthening and anti-friction lubrication.

Acknowledgment: This work was supported by Key Laboratory of Infrared Imaging Materials and Detectors, Shanghai Institute of Technical Physics, Chinese Academy of Sciences (No.IIMDKFJJ-17-06), National Natural Science Foundation of China (No. 51201143), China Postdoctoral Science Foundation (No. 2015M570794, No. 2018T110993).

Data Availability statement: The data used to support the findings of this study are available from the corresponding author upon request.

\section{References:}

[1]C.L.P. Pavithra, B.V. Sarada, K.V. Rajulapati, T.N. Rao, G. Sundararajan, A New Electrochemical Approach for the Synthesis of Copper-Graphene Nanocomposite Foils with High Hardness, Sci. Rep. 4(2015) 4049-4055. https://doi.org/10.1038/srep04049

[2]S. Chen, Y. Bi, H. Zhang, J. Liang, D. Wellburn, Effect of BN fraction on the mechanical and tribological properties of $\mathrm{Cu}$ alloy/BN self-lubricating sleeves, J. Compos. Mater. 49(2015). https://doi.org/10.1177/0021998314568330

[3]X. Chen, J. Tao, J. Yi, C. Li, R. Bao, Y. Liu, X. You, S. Tan, Balancing the strength and ductility of carbon nanotubes reinforced copper matrix composites 
with microlaminated structure and interdiffusion interface, Mater. Sci. Eng., A, 712(2018) 790-793. https://doi.org/10.1016/j.msea.2017.12.044

[4]S. Ren, J. Chen, X. He, X. Qu, Effect of matrix-alloying-element chromium on the microstructure and properties of graphite flakes/copper composites fabricated by hot pressing sintering, Carbon, $127 \quad$ (2018)412-423. https://doi.org/10.1016/j.carbon.2017.11.033

[5]C. Arnaud, F. Lecouturier, D. Mesguich, N. Ferreira, G. Chevallier, C. Estournès, A. Weibel, C. Laurent, High strength - High conductivity double-walled carbon nanotube - Copper composite wires, Carbon, 96(2016) 212-215.http://dx.doi.org/10.1016/j.scriptamat.2017.05.008

[6]K. Chu, X. Wang, F. Wang, Y. Li, D. Huang, H. Liu, W. Ma, F. Liu, H. Zhang, Largely enhanced thermal conductivity of graphene/copper composites with highly aligned graphene network, Carbon, 127(2018) 102-112.https://doi.org/10.1016/j.carbon.2017.10.099

[7]X. Xu, W. Li, Y. Wang, G. Dong, S. Jing, Q. Wang, Y. Feng, X. Fan, H. Ding, Study of the preparation of $\mathrm{Cu}-\mathrm{TiC}$ composites by reaction of soluble $\mathrm{Ti}$ and ball-milled carbon coating TiC, Results Phys. 9(2018) 486-492.https://doi.org/10.1016/j.rinp.2018.02.059

[8]P. Wang, H. Zhang, J. Yin, X. Xiong, C. Tan, C. Deng, Z. Yan, Wear and friction behaviours of copper mesh and flaky graphite- modified carbon/carbon composite for sliding contact material under electric current, Wear, 380-381(2017) 59-65.http://dx.doi.org/10.1016/j.wear.2017.02.045

[9]C. Deng, J. Yin, H. Zhang, X. Xiong, P. Wang, M. Sun, The tribological properties of $\mathrm{Cf} / \mathrm{Cu} / \mathrm{C}$ composites under applied electric current, Tribol. Int. 116(2017) 84-94.http://dx.doi.org/10.1016/j.triboint.2017.07.005

[10]W. Dang, S. Ren, J. Zhou, Y. Yu, Z. Li, L. Wang, Influence of $\mathrm{Cu}$ on the mechanical and tribological properties of $\mathrm{Ti}_{3} \mathrm{SiC}_{2}$, Ceram. Int. 42(2016) 9972-9980.http://dx.doi.org/10.1016/j.ceramint.2016.03.099

[11]M. Grandin, U. Wiklund, Wear phenomena and tribofilm formation of copper/copper-graphite sliding electrical contact materials, Wear, 398-399(2018) 227-235.https://doi.org/10.1016/j.wear.2017.12.012

[12]S.R. Bakshi, D. Lahiri, A. Agarwal, Carbon nanotube reinforced metal matrix composites - a review, Int. Mater. Rev. 55(2010) 41-64.https://doi.org/10.1179/095066009X12572530170543

[13]O.A.M. Elkady, A. Abu-Oqail, E.M.M. Ewais, M. El-Sheikh, Physico-mechanical and tribological properties of $\mathrm{Cu} / \mathrm{h}-\mathrm{BN}$ nanocomposites synthesized by PM route, J. Alloy. Compd. 625(2015) 309-317.http://dx.doi.org/10.1080/02670836.2015.1104018

[14]Z. Hu, G. Tong, D. Lin, C. Chen, H. Guo, J. Xu, L. Zhou, Graphene-reinforced metal matrix nanocomposites - a review, Mater. Sci. Technol. 32(2016) 930-953.http://dx.doi.org/10.1080/02670836.2015.1104018

[15]A. Bisht, M. Srivastava, R.M. Kumar, D. Lahiri, I. Lahiri, Strengthening mechanism in graphene nanoplatelets reinforced aluminum composite fabricated 
through spark plasma sintering, Mater. Sci. Eng., A, 695(2017) 20-28.http://dx.doi.org/10.1016/j.msea.2017.04.009

[16]S.C. Tjong, Recent progress in the development and properties of novel metal matrix nanocomposites reinforced with carbon nanotubes and graphene nanosheets, Mater. Sci. Eng., R, 281-350.http://dx.doi.org/10.1016/j.mser.2013.08.001

[17]A. Dorri Moghadam, E. Omrani, P.L. Menezes, P.K. Rohatgi, Mechanical and tribological properties of self-lubricating metal matrix nanocomposites reinforced by carbon nanotubes (CNTs) and graphene - A review, Compos. Part B, 77(2015) 402-420.http://dx.doi.org/10.1016/j.compositesb.2015.03.014

[18]D. Janas, B. Liszka, Copper matrix nanocomposites based on carbon nanotubes or graphene, Mater. Chem. Front.10(2017) 22-35.https://doi.org/10.1039/c7qm00316a

[19]H. Fang, S. Bai, C.P. Wong, "White graphene"- hexagonal boron nitride based polymeric composites and their application in thermal management, Compos. Commun. 2(2016) 19-24.http://dx.doi.org/10.1016/j.coco.2016.10.002

[20]B. Chen, J. Shen, X. Ye, L. Jia, S. Li, J. Umeda, M. Takahashi, K. Kondoh, Length effect of carbon nanotubes on the strengthening mechanisms in metal matrix composites, Acta Mater. 140(2017) 317-325.http://dx.doi.org/10.1016/j.actamat.2017.08.048

[21]H. Yue, L. Yao, X. Gao, S. Zhang, H. Zhang, E. Guo, X. Lin, B. Wang, Effect of ball-milling and graphene contents on the mechanical properties and fracture mechanisms of graphene nanosheets reinforced copper matrix composites, J. Alloy. Compd.

691(2017) 755-762.http://dx.doi.org/10.1016/j.jallcom.2016.08.303

[22]A. Liang, X. Jiang, X. Hong, Y. Jiang, Z. Shao, D. Zhu, Recent Developments Concerning the Dispersion Methods and Mechanisms of Graphene, Coatings, 8(2018) 33.https://doi.org/10.3390/coatings8010033

[23]X. Liu, E. Liu, J. Li, Q. Li, J. Sha, C. He, C. Shi, N. Zhao, In-situ synthesis of graphene nanosheets coated copper for preparing reinforced aluminum matrix composites, Mater. Sci. Eng., A, 709(2018) 65-71.http://dx.doi.org/10.1016/j.msea.2017.10.030

[24]X. Yang, T. Zou, C. Shi, E. Liu, C. He, N. Zhao, Effect of carbon nanotube (CNT) content on the properties of in-situ synthesis CNT reinforced Al composites, $\begin{array}{llll}\text { Mater. Sci. } & \text { Eng., }\end{array}$ 11-18.http://dx.doi.org/10.1016/j.msea.2016.02.062

[25]G. Zhang, X. Jiang, C. Qiao, Z. Shao, D. Zhu, M. Zhu, V. Valcarcel, Investigation of the Microstructure and Mechanical Properties of Copper-Graphite Composites Reinforced with Single-Crystal $\alpha-\mathrm{Al}_{2} \mathrm{O}_{3}$ Fibres by Hot Isostatic Pressing, Materials, 11(2018) 982.http://dx.doi.org/10.3390/ma11060982

[26]X. Zhang, C. Shi, E. Liu, C. He, F. He, L. Ma, Q. Li, J. Li, N. Zhao, In-situ space-confined synthesis of well-dispersed three-dimensional graphene/carbon nanotube hybrid reinforced copper nanocomposites with balanced strength and 
ductility, Compos. Part $\quad$ A, 103(2017)

178-187.https://doi.org/10.1016/j.compositesa.2017.09.010

[27]S.Y. Pak, H.M. Kim, S.Y. Kim, J.R. Youn, Synergistic improvement of thermal conductivity of thermoplastic composites with mixed boron nitride and multi-walled carbon nanotube fillers, Carbon, 50(2012) 4830-4838.http://dx.doi.org/10.1016/j.carbon.2012.06.009

[28]M. Yang, L. Weng, H. Zhu, F. Zhang, D. Zhang, T. Fan, Leaf-like carbon nanotube-graphene nanoribbon hybrid reinforcements for enhanced load transfer in copper matrix composites, Scripta. Mater. 138(2017) 17-21.http://dx.doi.org/10.1016/j.scriptamat.2017.05.024

[29]L. Jingrui, J. Xiaosong, S. Ru, S. Zhenyi, Z. Degui, L. Dan, Dispersion Characteristics of Multi-Walled Carbon Nanotubes and Carbon Nanoflakes with Oxygen Plasma, Nanosci. Nanotech. Let. 7(2015) 581-587.http://dx.doi.org/10.1166/nnl.2015.2007

[30]A. Bor, B. Ichinkhorloo, B. Uyanga, J. Lee, H. Choi, Cu/CNT nanocomposite fabrication with different raw material properties using a planetary ball milling process, Powder Technol.

563-573.http://dx.doi.org/10.1016/j.powtec.2016.06.042

[31]R. Shu, X. Jiang, J. Jiang, D. Zhu, Microstructure and mechanical properties of nano-carbon reinforced Cu-based powder metallurgy friction materials produced by hot isostatic pressing, Mater. Test. 60(2018) 809-817.http://dx.doi.org/10.3139/120.111217

[32]Y. Zhou, W. Gu, Chemical reaction and stability of $\mathrm{Ti}_{3} \mathrm{SiC}_{2}$ in $\mathrm{Cu}$ during high-temperature processing of $\mathrm{Cu} / \mathrm{Ti}_{3} \mathrm{SiC}_{2}$ composites, Z. Metallkd. 95(2004) 50-56.https://doi.org/10.3139/146.017911

[33]J. Xiaosong, L. Wanxia, L. Jingrui, S. Zhenyi, Z. Degui, Microstructures and mechanical properties of $\mathrm{Cu} / \mathrm{Ti}_{3} \mathrm{SiC}_{2} / \mathrm{C} / \mathrm{MWCNTs}$ composites prepared by vacuum hot-pressing sintering, J. Alloy. Compd.618 (2015) 700-706.http://dx.doi.org/10.1016/j.jallcom.2014.08.221

[34] V. Pasumarthi, Y. Chen, S.R. Bakshi, A. Agarwal, Reaction synthesis of $\mathrm{Ti}_{3} \mathrm{SiC}_{2}$ phase in plasma sprayed coating, J. Alloy. Compd. 484(2009) 113-117.http://dx.doi.org/10.1016/j.jallcom.2009.04.079

[35]X. Jiang, W. Liu, Y. Li, Z. Shao, Z. Luo, D. Zhu, M. Zhu, Microstructures and mechanical properties of $\mathrm{Cu} / \mathrm{Ti}_{3} \mathrm{SiC}_{2} / \mathrm{C} /$ graphene nanocomposites prepared by vacuum hot-pressing sintering and hot isostatic pressing, Compos. Part B, 141(2018) 203-213.https://doi.org/10.1016/j.compositesb.2017.12.050

[36]J.R. Lu, Y. Zhou, Y. Zheng, S.B. Li, Z.Y. Huang, Effects of Sintering Process on the Properties of $\mathrm{Ti}_{3} \mathrm{SiC}_{2} / \mathrm{Cu}$ Composite, Key Eng. Mater. 512-515(2012) 377-381.http://dx.doi.org/10.4028/www.scientific.net/KEM.512-515.377

[37]J.R. Lu, Y. Zhou, Y. Zheng, H.Y. Li, S.B. Li, Interface structure and wetting behaviour of $\mathrm{Cu} / \mathrm{Ti3SiC2}$ system, Adv. Appl. Ceram. 114(2014) 39-44.http://dx.doi.org/10.1179/1743676114Y.0000000185 
[38]J. Li, N. Lei, H. Hao, J. Zhou, A series of BCN nanosheets with enhanced photoelectrochemical performances, Chem. Phys. Lett. 672(2017) 99-104.http://dx.doi.org/10.1016/j.cplett.2017.01.054

[39]L. Wanxia, J. Xiaosong, S. Zhenyi, M. Defeng, Z. Degui, Z. Man, Tribological Behaviors of $\mathrm{Cu} / \mathrm{Ti}_{3} \mathrm{SiC}_{2} / \mathrm{C} / \mathrm{MWCNTs}$ Composites with Electric Current, J. Comput. Theor. Nanos. 12(2015) 2664-2672.http://dx.doi.org/10.1166/jctn.2015.4160

[40]X. Chen, J. Tao, J. Yi, Y. Liu, C. Li, R. Bao, Strengthening behavior of carbon nanotube-graphene hybrids in copper matrix composites, Mater. Sci. Eng., A, 718(2018) 427-436.https://doi.org/10.1016/j.msea.2018.02.006

[41]C. Bittencourt, X. Ke, G. Van Tendeloo, S. Thiess, W. Drube, J. Ghijsen, C.P. Ewels, Study of the interaction between copper and carbon nanotubes, Chem. Phys. Lett. 535(2012) 80-83.http://dx.doi.org/10.1016/j.cplett.2012.03.045

[42]C. Van Nguyen, Y. Deng, A. Bezold, C. Broeckmann, A combined model to simulate the powder densification and shape changes during hot isostatic pressing, Comput. Method. Appl. M. 315(2017) 302-315.http://dx.doi.org/10.1016/j.cma.2016.10.033

[43]H. Deng, J. Yi, C. Xia, Y. Yi, Mechanical properties and microstructure characterization of well-dispersed carbon nanotubes reinforced copper matrix composites, J. Alloy. Compd.

727(2017)

260-268.http://dx.doi.org/10.1016/j.jallcom.2017.08.131

[44]B. Faria, C. Guarda, N. Silvestre, J.N.C. Lopes, D. Galhofo, Strength and failure mechanisms of cnt-reinforced copper nanocomposite, Compos. Part B, 145(2018) 108-120.https://doi.org/10.1016/j.compositesb.2018.02.033

[45]M. Yang, L. Weng, H. Zhu, T. Fan, D. Zhang, Simultaneously enhancing the strength, ductility and conductivity of copper matrix composites with graphene nanoribbons, Carbon, 118(2017) 250-260.http://dx.doi.org/10.1016/j.carbon.2017.03.055

[46]Y. Chen, X. Zhang, E. Liu, C. He, C. Shi, J. Li, P. Nash, N. Zhao, Fabrication of in-situ grown graphene reinforced $\mathrm{Cu}$ matrix composites, Sci. Rep. 6(2016) 19363-19371.http://dx.doi.org/10.1038/srep19363

[47]X. Zhang, C. Shi, E. Liu, F. He, L. Ma, Q. Li, J. Li, W. Bacsa, N. Zhao, C. He, Achieving high strength and high ductility in metal matrix composites reinforced with a discontinuous three-dimensional graphene-like network, Nanoscale, 9(2017) 11929-11938.http://dx.doi.org/10.1039/c6nr07335b

[48]C. Xiong, T. Li, H. Li, Y. Zhu, T. Zhao, A. Dang, X. Ji, Y. Shang, M. Khan, Two-step approach of fabrication of interconnected nanoporous 3D reduced graphene oxide-carbon nanotube-polyaniline hybrid as a binder-free supercapacitor electrode, J. Alloy. Compd. 695(2017) 1248-1259.http://dx.doi.org/10.1016/j.jallcom.2016.10.253

[49]K.S. Novoselov, A.K. Geim, S.V. Morozov, D. Jiang, Y. Zhang, S.V. Dubonos, I.V. Grigorieva, A.A. Firsov, Electric field effect in atomically thin carbon films, Science, 306(2004) 666-669.http://dx.doi.org/10.1126/science.1102896 
[50]A. Boden, B. Boerner, P. Kusch, I. Firkowska, S. Reich, Nanoplatelet Size to Control the Alignment and Thermal Conductivity in Copper-Graphite Composites, Nano Lett. 14(2014) 3640-3644.http://dx.doi.org/10.1021/nl501411g

[51]J.G. Park, D.H. Keum, Y.H. Lee, Strengthening mechanisms in carbon nanotube-reinforced aluminum composites, Carbon, 95(2015) 690-698.http://dx.doi.org/10.1016/j.carbon.2015.08.112 